\title{
Primary Parotid Gland Sarcoidosis - Case Report
}

\author{
Kholood S Assiri and Mohammad S. Al-Ahmari \\ The Department of ORL-HNS, Khamis Mushayt General Hospital, Aseer, Kingdom of Saudi Arabia \\ Correspondence author: Kholood S Assiri, E-mail: dr.kholood1@ hotmail.com
}

\begin{abstract}
Background: Sarcoidosisis rare disorder worldwide and in Saudi Arabia. Extrapulmonary involvement are noticed as primary presentation seen in patients with sarcoidosis and can present at the same time as pulmonary sarcoidosis. Methods: A notolaryngology view of case report following a 44-year-old female presented with right painless parotid swelling for four months who was managed in Otolaryngology-Head and Neck Surgery (ORL-HNS) Clinic of Khamis Mushayt General Hospital and referred to rheumatology for evaluation and management and follow up for one year who completely cured. Conclusion: Primary parotid sarcoidosis is an uncommon disease. The diagnosis has been obtained from the surgical excision of the lesion.
\end{abstract}

Keywords: Otolaryngology-Head and Neck Surgery -

\section{INTRODUCTION}

Sarcoidosis is a systemic disease of unknown origin that is characterized by noncaseating granulomatous lesions. Primary otolaryngology manifestations of sarcoidosis are not commonly remarkable. The documented incidence of parotid gland involvement (either primary or secondary) is only $6 \%$. Extra pulmonary involvement can be present in up to $30 \%$ of patients with sarcoidosis and can present at the same time as pulmonary sarcoidosis ${ }^{(1)}$.

Parotid gland involvement is a wellrecognized extra-thoracic feature of sarcoidosis. However, the data on epidemiology and clinical characteristics of parotid gland disease in sarcoidosis are limited ${ }^{(2)}$. This article aimed at reporting an uncommon case of parotid lesion.

\section{CASE DESCRIPTION}

A 44-year-old female presented on February $17^{\text {th }}, 2017$, at the Otolaryngology-Head and Neck Surgery (ORL-HNS), Clinic of Khamis Mushayt General Hospital, complaining of right parotid swelling for Four months. The patient complaint was painless with no facial weakness or skin changes. Symptoms were progressive with no aggravating or relieving factors. No history of cervical lymphadenopathy, fever, loss of appetite or weight loss.

On examination, the patient was generally stable, but she had right firm parotid swelling, about two by two $\mathrm{cm}$, not tender with facial nerve intact. No lymphadenopathy.

Basic laboratory investigations were normal. CT scan revealed ill defined, heterogenous enhanced mass from right parotid gland, no sizable cervical lymphadenopathy Fig 1 .

Fine needle aspiration (FNA) done showed lymphoid aspirate with low cellularity and air dryness. However, this result doesn't give definitive diagnosis and need biopsy.

The decision was made to treat the patient operatively. Superficial parotidectomy was performed for right parotid mass. Under general anesthesia preauricular incision was made near the crease of the ear. We were very conscious not to distort the anatomy of the ear. A flap was made on the surface of the parotid gland to help expose the gland and tissue to be removed. Veins and nerve branches were identified. Facial nerve monitoring had been found to reduce nerve associated morbidities. Dissection of the nerves took place in order to avoid any stimulation while operating. Parotid tissue was removed (Fig 2,) and sent for histopathology examination, which revealed noncaseating epithelioid granuloma suggestive for sarcoidosis Fig 3.

Patient referred to rheumatology consultant and he ask for Antinuclear antibodies and Rheumatoid factors which showed negative result. CT lung done revealed unremarkable indication. Follow up of the case after one year revealed complete disappearance of her symptoms.

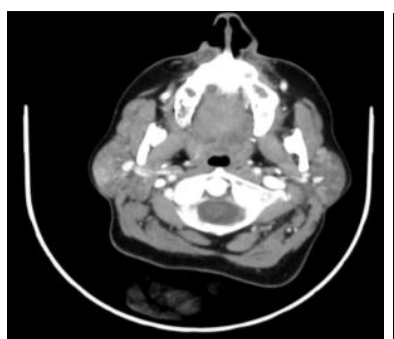

A

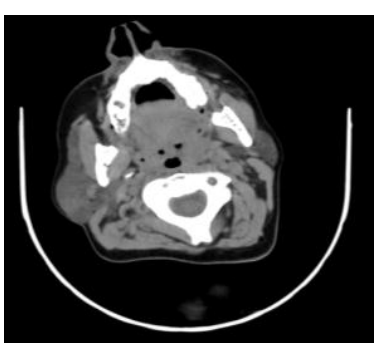

B
Fig. (1): (A,B) ill defined, heterogenous enhanced mass from right parotid gland 


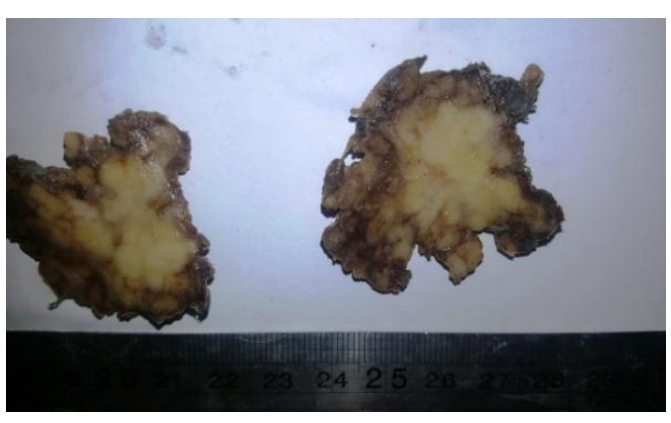

Fig. (2): Right parotid mass.

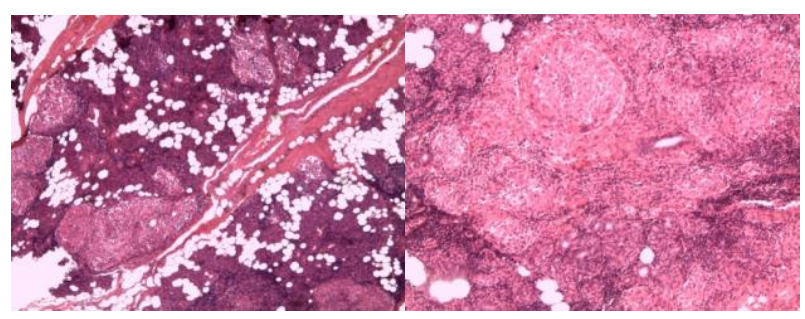

A B

Fig. (3): (A,B) Revealed non-caseating epithelioid granuloma suggestive for sarcoidosis.

\section{DISCUSSION}

Sarcoidosis is a multisystem disorder of unknown etiology that most commonly affects adults between 20 and 40 years of age. Lung and lymph node involvement is seen more commonly than other organs. Sarcoidosis is slightly more prevalent in women than men and it is more common in adults ${ }^{(3,4)}$. Parotid gland involvement occurs in $0.5-15 \%$ of patients of sarcoidosis ${ }^{(5)}$. The main clinical signs are painless swelling of parotid glands, cervical lymphadenopathy and xerostomia ${ }^{(6)}$. In our case, only painless swelling of parotid gland was present.

Our patient was a 44-year-old female presented with right painless parotid swelling for four months with no any other symptoms.

Biopsy, radiography and serum ACE level are important in the diagnostic process. Histologically and cytopathologically noncaseating granulomas, composed of epithelioid cells, histiocytes and giant cells are characteristic features of sarcoidosis ${ }^{(7,8)}$.

There is no specific laboratory test for Sarcoidosis. Markersof activity include raised levels of serum angiotensinconverting enzyme (ACE), abnormal calcium metabolism, apositive Kveim-
Siltazbach skin test and radioactive galliumscanning (Gallium-67 citrate) of parotid gland ${ }^{(9,10)}$.

The diagnosis of Sarcoidosis.is confirmed by the presence of non-caseatingepithelioid cell granulomas on histopathology of the affected parotid gland. Since non-caseating granulomas are occasionally seen in tuberculosis, special stains such as Ziehl-Neelsen may be used to rule out the above condition ${ }^{(6)}$.

The main treatment of sarcoidosis is corticosteroids and nonsteroidal anti-inflammatory drugsalthough in the literature some patients have been found to be treated surgically (1, 11). Spontaneous regression of this disease has been reported ${ }^{(12)}$. In our case, prednisone and antiinflammatory drugs were used for treatment.

\section{CONCLUSION}

In Conclusion, Sarcoidosis is a complex disorder that often involves the head and neck. Despite the presence of strong clinical evidence, tissue diagnosis and imaging are needed for confirmation of the disease.

\section{ACKNOWLEDGMENT}

We thank the Khamis Mushayt General Hospital for the facilitating the follow up the child in this report.

\section{REFERENCES}

1. Genetics Home Reference (2017): Arterial tortuosity syndrome. Available from: https:// ghr. nlm. nih. gov/ condition/arterial-tortuositysyndrome

2. Naunheim M, Walcott B, Nahed B, MacRae C, Levinson J, Ogilvy C (2011): Arterial Tortuosity Syndrome with Multiple Intracranial Aneurysms. Archives of Neurology, 68(3):369-71.

3. Callewaert B, De Paepe A, Coucke P (2014): Arterial Tortuosity Syndrome. In: Adam MP, Ardinger HH, Pagon RA, et al., editors. GeneReviews ${ }^{\circledR}$ Seattle (WA): University of Washington, Seattle; 1993-2017. Available from: https:// www. ncbi. nlm. nih. gov/ books/ NBK253404/

4. Ertugrul A (1967): Diffuse Tortuosity and Lengthening of the Arteries. Circulation, 36(3):400-407. 
5. Ritelli M, Drera B, Vicchio M, Puppini G, Biban P, Pilati M et al. (2009): Arterial tortuosity syndrome in two Italian paediatric patients. Orphanet Journal of Rare Diseases, $4(1): 20$.

6. Loup O, Daubeney P, Saggar A, Rubens M, Naqvi N, Ghez O (2013): Severe Arterial Tortuosity in an Asymptomatic Infant with Coarctation. Circulation: Cardiovascular Imaging, 6(3):487-490.

7. Lee $\mathbf{Y}$, Huang $\mathrm{H}$, Chang $\mathrm{C}$, Cheng $\mathrm{C}$, Chen Y (2010): Mitochondrial GLUT10 facilitates dehydroascorbic acid import and protects cells against oxidative stress: mechanistic insight into arterial tortuosity syndrome. Human Molecular Genetics, 19(19):3721-3733.

8. Castori M, Ritelli M, Zoppi N, Molisso L, Chiarelli N, Zaccagna F et al. (2012): Adult presentation of arterial tortuosity syndrome in a 51-year-old woman with a novel homozygous c. $1411+1 \mathrm{G}>\mathrm{A}$ mutation in the SLC2A10 gene. American Journal of Medical Genetics Part A., 158A(5):1164-1169.
9. Coucke P (2003): Homozygosity mapping of a gene for arterial tortuosity syndrome to chromosome 20q13. Journal of Medical Genetics, 40(10):747-751.

10. Faiyaz-Ul-Haque M, Zaidi S, Wahab A, Eltohami A, Al-Mureikhi M, Al-Thani G et al. (2008): Identification of a p.Ser81Arg encoding mutation in SLC2A10 gene of arterial tortuosity syndrome patients from 10 Qatari families. Clinical Genetics, 74(2):189-193.

11. Callewaert B, Willaert A, KerstjensFrederikse W, De Backer J, Devriendt K, Albrecht B et al. (2008): Arterial tortuosity syndrome: clinical and molecular findings in 12 newly identified families. Human Mutation, 29(1):150-158. 